\title{
Kinetics of enzymatic deacetylation of chitosan
}

\author{
Malgorzata M. Jaworska
}

Received: 5 July 2011/Accepted: 3 January 2012/Published online: 20 January 2012

(C) The Author(s) 2012. This article is published with open access at Springerlink.com

\begin{abstract}
The current paper reports on an investigation of the kinetics of chitosan deacetylation by chitin deacetylase isolated from Absidia orchidis vel coerulea. The reaction rate was correlated with the concentration of GlcNHAc units of the polymer. It is shown that the process follows the Michaelis-Menten mechanism. Modification of the Michaelis-Menten equation by introducing the activity of the enzyme instead of its concentration was tested and found to give a better approximation to the experimental data than the original Michaelis-Menten model. Parameters for both the original and the modified Michaelis-Menten equations are also proposed.
\end{abstract}

Keywords Chitin deacetylase - Chitosan - Enzyme activity · Modified Michaelis-Menten equation ·

Kinetics of impure enzyme preparation .

Nonhomogeneous preparation

\section{Introduction}

Chitin deacetylase is the only enzyme that is able to hydrolyze the linkage between the acetyl and amine groups in the units of $\mathrm{N}$-acetylglucosamine

M. M. Jaworska ( $\square)$

Faculty of Chemical and Process Engineering,

Warsaw University of Technology, ul. Warynskiego 1,

00-645 Warsaw, Poland

e-mail: jaworska@ichip.pw.edu.pl
(GlcNHAc) of chitin or chitosan, transforming them into the glucosamine $\left(\mathrm{GlcNH}_{2}\right)$ units according to the reaction:

$$
\begin{aligned}
& -\mathrm{GlcNHAc}+\mathrm{H}_{2} \mathrm{O} \stackrel{\text { chitin deacetylase }}{\longrightarrow}-\mathrm{GlcNH}_{2} \\
& +\mathrm{AcOH} .
\end{aligned}
$$

This transformation can be used for enzymatic modification of chitosan to obtain polymers with a lower degree of acetylation (DA, the content of GlcNHAc in a polymer chain), as several properties of chitosan (e.g. bioactivity, biodegradability, sorption capacity) are related to acetylation degree, varying with variation in DA The reaction of deacetylation can be carried out chemically with concentrated $\mathrm{NaOH}$ solution (approx. $50 \%, 90-120{ }^{\circ} \mathrm{C}$ ), but this causes simultaneous degradation of the chitosan chain, so the polymer can be degraded even to oligomers. Contrary to the chemical process, enzymatic deacetylation avoids polymer degradation and a polymer with the same degree of polymerisation and much smaller acetylation degree is obtained.

Chitin deacetylase (ChD) exists as intracellular enzyme (e.g. from Mucor rouxi, Absidia orchidis) or as extracellular enzyme (e.g. produced by Colletotrichum lindemuthianum, Aspergillus nidulans). The mode of action of these two forms of chitin deacetylase is different. It was suggested that for extracellular $\mathrm{ChD}$ it is a "multiple chain mechanism" while for intracellular $\mathrm{ChD}$ it is a "multiple attack" mechanism and the deacetylation starts from nonreducing end of chitin/ chitosan chain (Tsigos et al. 2000; Blair et al. 2006). 
Industrial application of an enzyme needs knowledge of the kinetics of the process. Currently the literature shows several possible kinetic models for enzymatic deacetylation of chitosan. It has been suggested that the process with chitin deacetylase separated from Mucor rouxi follows the MichaelisMenten mechanism (Martinou et al. 1998) but, depending on the degree of acetylation of the polymer, different values of $\mathrm{K}_{\mathrm{M}}$ were reported and values of $\mathrm{V}_{\max }\left(\right.$ or $\mathrm{k}_{3}$ ) were not presented. Contrary to these observations, Dunkel and Knorr (1994), Amorim et al. (1996) as well as Jaworska and Konieczna (2003) have suggested some deviations from the MichaelisMenten mechanism. Dunkel and Knorr (1994) did not observe the saturation-type curve for the enzyme isolated from Mucor rouxii DSM 1191, so they concluded that the kinetics are not of the MichaelisMenten type. Amorim et al. (1996) suggested that the kinetics for chitin deacetylase isolated from Cumingamells bertholletiae followed the Hill affinity distribution rather than a Michaelis-Menten mechanism, probably showing allosteric behaviour. Similar observations were reported in the preliminary investigations of Jaworska and Konieczna (2004) for the enzyme isolated from Absidia orchidis vel coerulea NCAIM F0642. Data presented in the form of a LineweaverBurk plot did not give a linear relationship, but linearity was obtained for the plot of $1 /$ (reaction rate)

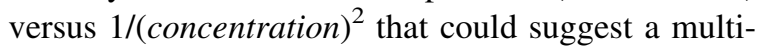
site cooperative mechanism often described by the Hill's equation. The literature also presents kinetic data for enzymatic deacetylation of chitin oligosaccharides (Tokuyasu et al. 1996; Alfonso et al. 1995). Although authors have suggested the MichaelisMenten mechanism for the deacetylation process, they reported that changes in values of $\mathrm{V}_{\max }$ (or $\mathrm{k}_{3}$ ) and/or $K_{M}$ were observed with changes in the degree of polymerisation of the oligomers ( $\mathrm{DP}=2-6$ ) (Table 1). Hence these parameters cannot be applied directly to the deacetylation of chitosan.

The literature data to date indicates that the kinetics of enzymatic deacetylation of chitosan has not been presented in a satisfactory way. Several kinetic models for the process have been considered: simple enzymatic kinetics according to the Michaelis-Menten model; the model of allosteric interaction; or a model of multisite cooperation. Additionally the parameters of the models changed with a change in the substrate: either with a change of degree of polymerization (oligomers) or with a change in the degree of acetylation (chitosan). This situation suggests that every chitosan substrate would require a new set of $\mathrm{K}_{\mathrm{M}}$ and $\mathrm{V}_{\max }\left(\mathrm{k}_{3}\right)$ values depending on the degree of acetylation, hence none of the previously reported sets of parameters can be used as universal ones suitable for deacetylation of any chitosan.

The aim of the current work was to investigate the kinetics of deacetylation of chitosan and to present a procedure for evaluation of kinetics parameters that would be suitable for chitosans with different acetylation degree. In this work, chitin deacetylase separated from Absidia orchidis vela coerulea NCAIM F 00642 was used.

\section{Materials and methods}

Chitin deacetylase

Chitin deacetylase was separated from Absidia orchidis vela coerulea NCAIM F 00642. The fungi were cultivated in a 7.0-L batch culture $\left(26{ }^{\circ} \mathrm{C}, \mathrm{pH} 5.5\right.$, YPG nutrient medium (Jaworska and Konieczna 2001)) and separated from the nutrient medium by centrifugation $(6,000 \mathrm{rpm})$. Next the biomass was frozen and than slowly thawed and homogenised, and the crude cell extract separated (centrifugation, 6,000 rpm) and salted out with ammonium sulphate (80\% saturation) overnight at $4-6{ }^{\circ} \mathrm{C}$. The solution was diafiltrated with $\mathrm{HCl}(\mathrm{pH} 4.0)$ to remove ammonium sulphate (using a PES membrane module Vivaflow 50 (Sartorius) with a $10 \mathrm{kDa}$ cut-off) and than concentrated by ultrafitration (the same membrane module). This solution was used in the experiments. The enzyme was accompanied by one additional protein (SDS electrophoresis not shown) with a trace concentration (as indicated by a much lower intensity of the bar) that stabilised its activity during storage.

The presence of chitosanolytic enzymes was monitored by viscometric measurements and reducing sugar concentration measurements, but their activity was not observed (changes in the range of accuracy of analytical methods were detected, and they did not exceed $5 \%$ of initial values).

Enzyme activity was defined as the amount of enzyme that releases $0.1 \mathrm{mg}$ of acetic acid during $1 \mathrm{~min}$ of the reaction at optimal conditions $(\mathrm{pH}=4.0$, $\mathrm{T}=50^{\circ} \mathrm{C}$ and with concentration of GlcNHAc 
Table 1 Kinetic parameters of the Michaelis-Menten equation

\begin{tabular}{|c|c|c|c|c|}
\hline Source & Substrate & $\mathrm{K}_{\mathrm{M}}$ & $\mathrm{V}_{\max }$ & Ref. \\
\hline \multirow{5}{*}{$\begin{array}{l}\text { Colletotrichum lindemuthianum } \\
\text { ATCC } 56676\end{array}$} & $(\mathrm{GlcNAc})_{2}$ & $18.4 \mathrm{mM}$ & $16.2^{*}$ & \multirow[t]{5}{*}{ Tokuyasu et al. (1996) } \\
\hline & $(\mathrm{GlcNAc})_{3}$ & $11 \mathrm{mM}$ & $11.3^{*}$ & \\
\hline & $(\mathrm{GlcNAc})_{4}$ & $0.6 \mathrm{mM}$ & $184 *$ & \\
\hline & $(\mathrm{GlcNAc})_{5}$ & $0.4 \mathrm{mM}$ & $158 *$ & \\
\hline & $(\mathrm{GlcNAc})_{5}$ & $69.9 \mu \mathrm{M}$ & - & \\
\hline \multirow[t]{5}{*}{ Aspergillus nidulans CECT 2544} & $(\mathrm{GlcNAc})_{2}$ & $0.09 \mathrm{mM}$ & $4.0 * *$ & \multirow[t]{5}{*}{ Alfonso et al. (1995) } \\
\hline & $(\mathrm{GlcNAc})_{3}$ & $0.15 \mathrm{mM}$ & $5.3 * *$ & \\
\hline & $(\mathrm{GlcNAc})_{4}$ & $0.50 \mathrm{mM}$ & $10.0 * *$ & \\
\hline & $(\mathrm{GlcNAc})_{5}$ & $2.50 \mathrm{mM}$ & $33.3 * *$ & \\
\hline & $(\mathrm{GlcNAc})_{6}$ & $0.12 \mathrm{mM}$ & $5.9 * *$ & \\
\hline \multirow[t]{3}{*}{ Mucor rouxii ATCC 24905} & Chitosan AD $8 \%$ & $2.1 \mathrm{mg} / \mathrm{mL}$ & - & \multirow[t]{3}{*}{ Martinou et al. (1998) } \\
\hline & Chitosan AD 35\% & $1.7 \mathrm{mg} / \mathrm{mL}$ & - & \\
\hline & Chitosan Ad $62 \%$ & $2.1 \mathrm{mg} / \mathrm{mL}$ & - & \\
\hline
\end{tabular}

* $\mu \mathrm{M} \mathrm{GlcN} /(\min * \mathrm{mg}$ białka $)$

** $\mathrm{nmol} / \mathrm{min}$

close to saturation, $\left.\mathrm{C}_{\mathrm{GlcNHAc}}=2.26 \mathrm{~g} / \mathrm{L}\right), 1 \mathrm{U}=$ $0.1 \mathrm{mg} / \mathrm{min}$.

\section{Chemicals}

The chitosan used in all the experiments was kindly donated by Gillet-Mahtani-Chitosan (France/India). It was of medium molecular weight (viscosity of $1 \%$ solution in $1 \%$ acetic acid solution at $25^{\circ} \mathrm{C}$ $\mu=85 \mathrm{~Pa} \times \mathrm{s}$, according to the producer data), and $\mathrm{AD}=39.8 \%$ (determined from the IR spectrum using the procedure of Domszy and Roberts (Domszy and Roberts 1985)). Chitosan (5.0 g) was mixed with $500 \mathrm{~mL}$ of $\mathrm{HCl}$ solution (pH 4.0). Next $0.1 \mathrm{M} \mathrm{HCl}$ was added in small portions (1-2 $\mathrm{mL}$ ) to complete polymer dissolution (the $\mathrm{pH}$ was controlled during the dissolution and kept constant at $\mathrm{pH} 4.0 \pm 0.1$ ) and it was adjusted to a final volume of $1.0 \mathrm{~L}$ with a $\mathrm{HCl}$ solution ( $\mathrm{pH}$ 4.0). The lower concentration of GlcNAc unit in reaction mixture was obtained by dilution of prepared solution with $\mathrm{HCl}(\mathrm{pH} 4.0)$ in a volumetric flask.

All other chemicals were analytical grade and purchased from POCH (Poland).

Kinetics experiments

$100 \mathrm{~mL}$ of the chitosan solution with the required concentration of GlcNAc units, prepared as described above, were preheated $\left(50{ }^{\circ} \mathrm{C}\right)$ for $20 \mathrm{~min}$ and the chitin deacetylase solution was preheated separately for $2 \mathrm{~min}$ at $50{ }^{\circ} \mathrm{C}$. The reaction was initiated by adding the enzyme to the reaction solution and was continued at $50{ }^{\circ} \mathrm{C}$ in a stirred $(250 \mathrm{rpm})$ thermostated batch reactor. At preselected time intervals the reaction mixture was sampled $(2.0 \mathrm{~mL})$ and the reaction was stopped immediately by addition of $0.10 \mathrm{~mL} 1.0 \mathrm{M} \mathrm{NaOH}$ to the sample. The precipitated chitosan was separated by centrifugation and the released acetic acid concentration in the clear supernatant solution was determined.

The reaction rate in each experiment was calculated as an initial reaction rate on the basis of the changes of the concentration of acetic acid in time.

Analytical methods

Protein concentration was determined according to the Bradford method using a ready-made reagent from Biorad (USA, cat. No. 500-0006) and bovine serum albumin as a standard.

Acetic acid concentration in the clear solution was analyzed by the HPLC method using an isocratic system (Varian ProStar 210) with a HyperREZ XP Organic acid column $\left(60{ }^{\circ} \mathrm{C}\right)$ and a HyperREZ XO Carbohydrate $\mathrm{H}^{+}$Guard Column, $0.0025 \mathrm{M} \mathrm{H}_{2} \mathrm{SO}_{4}$ as eluent $(0.5 \mathrm{~mL} / \mathrm{min})$, and a refractometer detector (Varian ProStar 350). The quantification limit was evaluated at $5 \mathrm{nmol} / \mathrm{mL}$ with a standard deviation of $8 \%$ of the mean value. 
The method was validated for acetic acid determination in chitosan- $\mathrm{HCl}$ ( $\mathrm{pH} 4.0)$ solutions.

\section{Results}

Experiments were carried out for 5 different concentrations of enzyme, and 8-9 concentrations of chitosan for each concentration of the enzyme. Four series of experiments were used for evaluation of the parameters in a kinetics equation while the fifth was used as independent data for verification of the proposed kinetics equation.

Experiments were carried out at optimal $\mathrm{pH}$ (4.0) and at temperature of $50{ }^{\circ} \mathrm{C}$ which was $5{ }^{\circ} \mathrm{C}$ lower than the optimal. The initial reaction rate $(v,[(\mathrm{mg}$ $\mathrm{AcOH} / \mathrm{L}$ )/min]) of enzymatic deacetylation was correlated with the concentration of GlcNAc units as a substrate (their concentration, $\mathrm{C}_{\mathrm{GlcNAc}}$, being calculated on the basis of the chitosan concentration and its degree of deacetylation) as it was presented earlier (Jaworska et al. 2009). Using this concept, a simple, universal relationship can be obtained which can be applied to any chitosan with a known DA value without need to introduce any additional parameters to correct the particular DA value of the polymer.

Results of the enzymatic deacetylation of chitosan are presented as a Lineweaver-Burk plot in Fig. 1.

In all cases the linearity between reverse reaction rate and reverse concentration can be readily observed. This linearity has been confirmed also by an EadieHofstee plot and a Wolf plot (data not presented). The coefficients of determination $\left(\mathrm{R}^{2}\right)$ varied from 0.962 to
0.968 what indicate a good approximation to experimental data. On the basis of these observations, the agreement with the Michaelis-Menten model was assumed. Although the mechanism itself was not investigated, deviations from the Michaelis-Menten model were not observed and this equation has been chosen for the mathematical model of enzymatic deacetylation of chitosan as it has a simple, elegant form and describes the experimental data with a sufficient accuracy.

$v_{\mathrm{AcOH}}=\frac{\mathrm{V}_{\mathrm{max}} \cdot C_{\mathrm{GlcNAc}}}{\mathrm{K}_{\mathrm{M}}+\mathrm{C}_{\mathrm{GlcNAc}}}=\frac{\mathrm{k}_{3} \cdot \mathrm{C}_{\mathrm{E}} \cdot \mathrm{C}_{\mathrm{GlcNAc}}}{\mathrm{K}_{\mathrm{M}}+\mathrm{C}_{\mathrm{GlcNAc}}}$.

The parameters in Michaelis-Menten equation have been evaluated on the basis of the original experimental data $\left(v_{\mathrm{AcOH}}\right.$ vs. $\left.\mathrm{C}_{\mathrm{GlcNAc}}\right)$ using the nonlinear regression method. The parameters of the Michaelis-Menten equation are presented in Table 2.

The presented data show that the variation in the Michaelis constant $\left(\mathrm{K}_{\mathrm{M}}\right)$ is small and acceptable, but large differences in the reaction rate constant $\left(\mathrm{k}_{3}\right)$ are observed; with the highest value $(0.876)$ being nearly $90 \%$ larger that the lowest value (0.477). Such significant differences for the calculated values of $\mathrm{k}_{3}$ cannot be accepted for a kinetic model. It can be easily observed when we compare experimental and theoretical data calculated on the basis of the mean values of $\mathrm{K}_{\mathrm{M}}$ and $\mathrm{k}_{3}$, Fig. 2.

The proposed model, based on the mean values presented in Table 2, describes only two experimental series well (Fig. 2B), while showing significant differences for the other two experimental series (Fig. 2A). It also shows significant differences for the
Fig. 1 The LineweaverBurk plot for the enzymatic deacetylation of chitosan
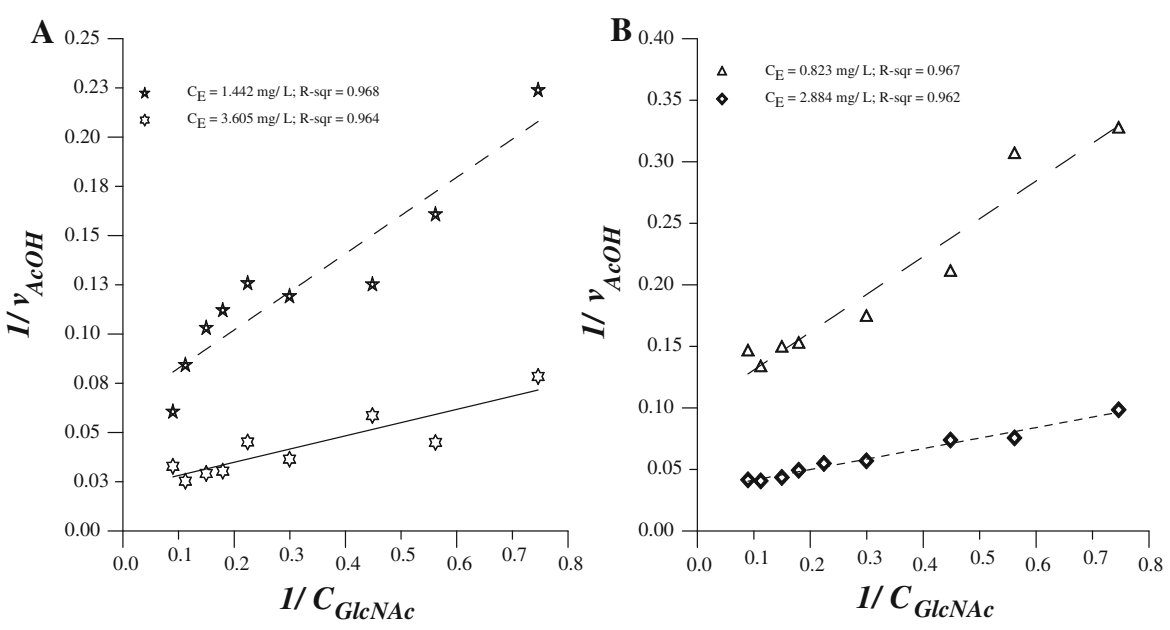

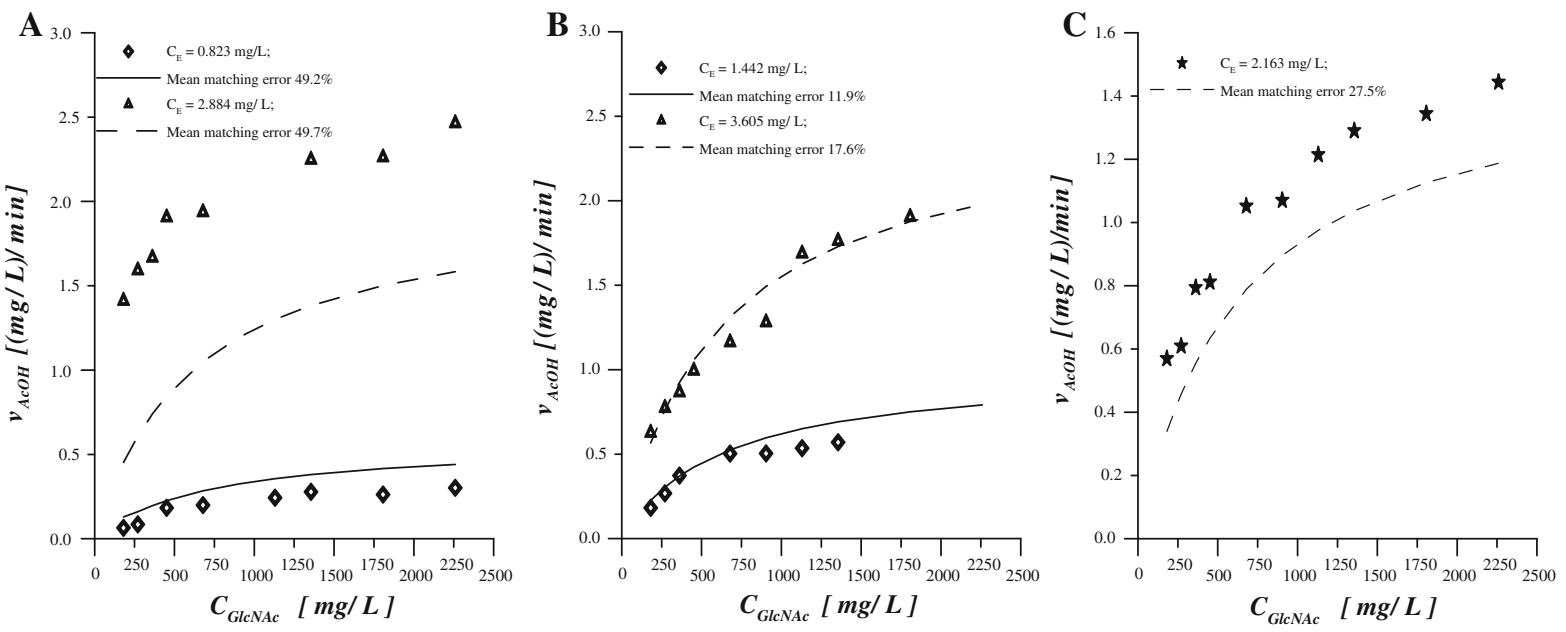

Fig. 2 Comparison of experimental data with the model (Eq. 1). A, B experimental data showed in Fig. 1; $\mathbf{C}$ data for additional experiment. The mean values of $\mathrm{K}_{\mathrm{M}}$ and $\mathrm{k}_{3}$ (Table 2) were used for calculation of the model

Table 2 Parameters of the Michaelis-Menten equation, according to Eq. 1

\begin{tabular}{lrl}
\hline $\begin{array}{l}\mathrm{C}_{\mathrm{E}} \\
(\mathrm{mg} / \mathrm{L})\end{array}$ & $\mathrm{K}_{\mathrm{M}}(\mathrm{mg} / \mathrm{L})$ & $\mathrm{k}_{3}(1 / \mathrm{min})$ \\
\hline 0.822 & 693 & 0.477 \\
1.442 & 532 & 0.577 \\
2.884 & 533 & 0.876 \\
3.605 & 750 & 0.737 \\
Mean $\pm \mathrm{SD}$ & $627 \pm 111$ & $0.667 \pm 0.176$ \\
\hline
\end{tabular}

experimental results used for the model verification (Fig. 2C). Such large differences are not acceptable in kinetic studies.

Chitin deacetylase is an enzyme that is not commercially available and it was separated from the biomass in laboratory conditions, so preparations with different initial activity could be obtained. It was also not purified to homogeneity because the homogeneous enzyme preparation showed a very short stability and lost its activity in 1-2 days, while enzyme preparations with some amount of impurities were stable for 2-3 weeks when stored under refrigerated conditions. The impurities present in the nonhomogeneous preparation stabilized its activity.

In such a case, when operating with preparations with different initial activity and not purified to homogeneity, the kinetics studies become extremely complicated. The concentration of enzyme $\left(C_{E}\right)$ cannot be used in the kinetic equation as the real $\mathrm{C}_{\mathrm{E}}$ is often not known. The concentration of proteins in a preparation (usually used as $\mathrm{C}_{\mathrm{E}}$ ) also contains an unknown concentration of impurities. Thus, instead of using the concentration of the enzyme it was decided to correlate the reaction rate with the "concentration of activity" (U/L), as activity is correlated only with the enzyme taking part in the reaction. The maximal reaction rate, $\mathrm{V}_{\max }$, is the parameter that depends on enzyme concentration. Thus the maximal reaction rate $\mathrm{V}_{\text {max }}$ can be modified:

$\mathrm{V}_{\max } \sim \mathrm{C}_{\mathrm{E}} \sim \frac{\mathrm{U}}{\mathrm{L}}$.

The "concentration of activity" can be calculated on the basis of the specific activity (U/mg) of the preparation and the concentration of proteins $\left(\mathrm{C}_{\mathrm{p}}\right)$ in it:

$\frac{\mathrm{U}}{\mathrm{L}}=\frac{\mathrm{U}}{\mathrm{mg}} \times \mathrm{C}_{\mathrm{p}}=\left(\frac{\mathrm{U}}{\mathrm{mg}}\right) \times \frac{\mathrm{mg}}{\mathrm{L}}$.

Data presented in Fig. 1 indicated that the kinetics of the enzymatic deacetylation of chitosan can be described by the Michaelis-Menten equation, thus this relationship was used in the modified form:

$v_{\mathrm{AcOH}}=\frac{\kappa \cdot\left(\frac{\mathrm{U}}{\mathrm{mg}}\right) \cdot \mathrm{C}_{\mathrm{P}} \cdot \mathrm{C}_{\mathrm{GlcNAc}}}{\mathrm{K}_{\mathrm{M}}+\mathrm{C}_{\mathrm{GlcNAc}}}$.

Here, the reaction rate constant $\left(\mathrm{k}_{3}, \min ^{-1}\right)$ was replaced by the $\kappa$ parameter (unitless) because the activity itself contains time in its units $(1 \mathrm{U}=[\mathrm{mg} /$ $\min ]$ ), so $\kappa$ can not be considered as a rate constant. It should be emphasized that the usage of "concentration of activity" does not change the mechanism of the 

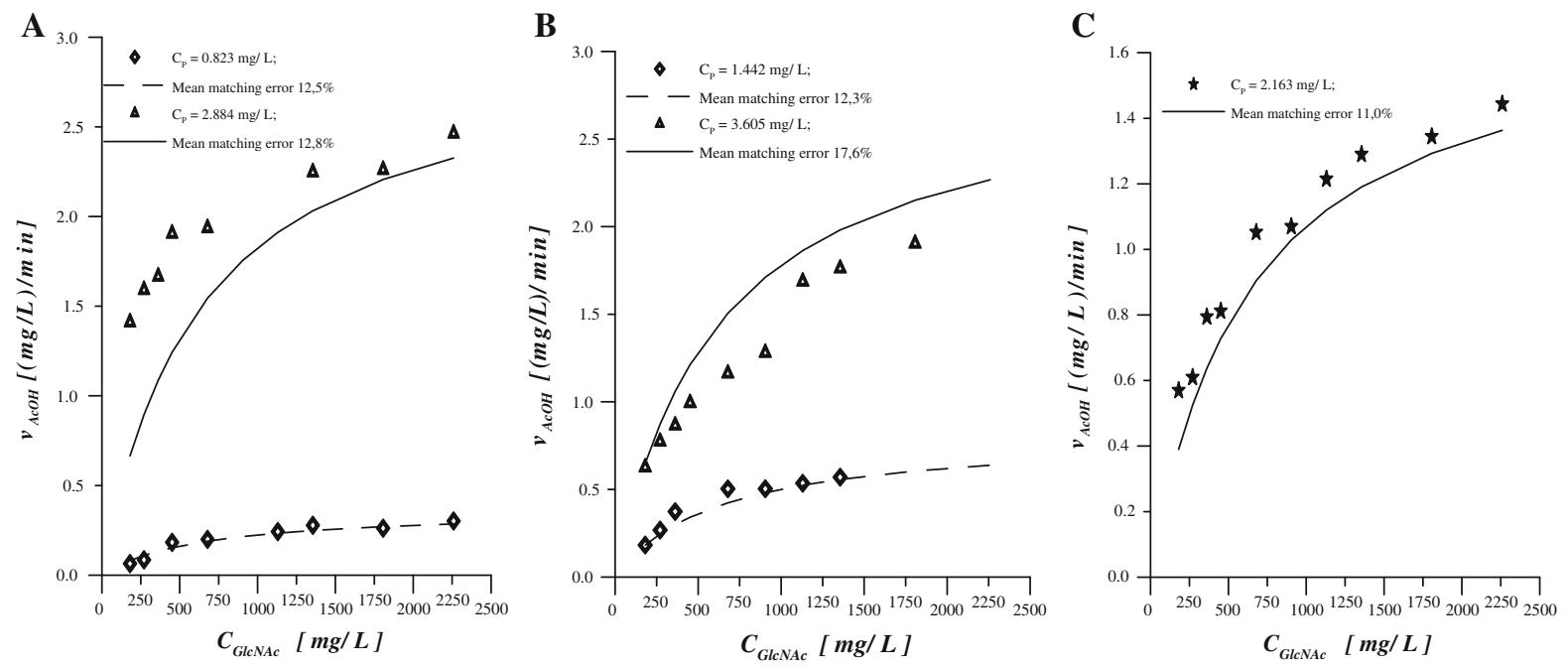

Fig. 3 Comparison of experimental data with the model (Eq. 4). A, B experimental data showed in Fig. 1; C data for additional experiment. The mean values of $\mathrm{K}_{\mathrm{M}}$ and $\kappa$ (Table 3) were used for calculation of the model

Michaelis-Menten model, but changes only the way the enzyme concentration is introduced into the equation.

The parameters of the modified Michaelis-Menten equations were calculated on the basis of the original experimental data using the method of non-linear regression, Table 3.

The value of the Michaelis constant $\mathrm{K}_{\mathrm{M}}$ remained the same, but much smaller variations in values of the parameter $\kappa$ can be readily observed. The difference between the largest and the smallest calculated value was approximately $18 \%$ of the smallest value. Such difference, in our opinion, is acceptable in kinetic experiments. The mean values of $\mathrm{K}_{\mathrm{M}}$ and $\kappa$ presented in Table 3 were used to calculate the model of enzymatic deacetylation of chitosan that was compared with the experimental data, Fig. 3.

The modified Michaelis-Menten model fits the experimental data much better than the model calculated on the basis of the original equation.

\section{Conclusions}

The Michaelis-Menten equation, although having several disadvantages, is the most popular equation describing the kinetics of enzymatic reactions. It is simple and usually reflects the experimental data well. However when the initial activity of the enzyme preparation is not repeatable, significant differences
Table 3 Parameters for the modified Michaelis-Menten equation, according to Eq. 4

\begin{tabular}{lrll}
\hline $\mathrm{C}_{\mathrm{p}}(\mathrm{mg} / \mathrm{L})$ & $\mathrm{K}_{\mathrm{M}}(\mathrm{mg} / \mathrm{L})$ & $\mathrm{U}$ units & \multicolumn{1}{l}{$\kappa$} \\
\hline 0.822 & 693 & 3.67 & 0.1301 \\
1.442 & 532 & 4.68 & 0.1231 \\
2.884 & 534 & 8.54 & 0.1187 \\
3.605 & 750 & 6.66 & 0.1107 \\
Mean $\pm \mathrm{SD}$ & $627 \pm 111$ & - & $0.1207 \pm 0.0082$ \\
\hline
\end{tabular}

between data and model can be observed. These differences will be greater when the enzymatic preparation contains impurities or when using preparations with different activities. To eliminate these disadvantages it is proposed to correlate $\mathrm{V}_{\max }$ with the activity of the enzyme instead of with its concentration. This modification has been found to give a much better approximation of the experimental data than did the original equation.

The kinetics of the deacetylation of chitosan by chitin deacetylase has not previously been described satisfactorily. Some earlier kinetic data suggested Michaelis-Menten kinetics, but the kinetic parameters would be difficult to transfer into other experiments. The current investigation confirms that the MichaelisMenten model can be used for enzymatic deacetylation of chitosan and the evaluated parameters can be easily transferred to any chitosans used in further experiments. 
Acknowledgments The author wants to thanks Ewa Konieczna-Mordas, MS for her technical assistant and Prof George Roberts from University of Nottingham for fruitful discussion.

Open Access This article is distributed under the terms of the Creative Commons Attribution Noncommercial License which permits any noncommercial use, distribution, and reproduction in any medium, provided the original author(s) and source are credited.

\section{References}

Alfonso C, Nuero OM, Santamaria R, Reyes F (1995) Purification of heat-stabile chitin deacetylase from Aspergillus nidulans and its role in cell wall degradation. Curr Microbiol 30:49-54

Amorim RVS, Ledingham WM, Fukushima K, Campos-Takaki GM (1996) Screening of chitin deacetylase from Mucoralean strains (Zygomycetes) and its relationship to cell growth rate. J Ind Microbiol Biotechnol 32:19-23

Blair DE, Hekmat O, Schuttelkopf AW, Shrestha B, Tokuyasu K, Withers SG, van Aalten DMF (2006) Structure and mechanism of chitin deacetylase from the fungal pathogen Colletotrichum lindemuthianum. Biochemistry 45:94169426
Domszy JG, Roberts GAF (1985) Evaluation of infrared spectroscopic techniques for analyzing chitosan. Makromol Chem 186:1671-1673

Dunkel Ch, Knorr D (1994) Enhancement of chitin deacetylase activity in Mucor rouxii and Absidia coerulea with chitin and its detection with a non-radioavtive substrate. Food Biotech 8:67-74

Jaworska MM, Konieczna E (2001) The influence of supplemental components in nutrient medium on chitosan formation by the fungus Absidia orchidis. Appl Microbiol Biotechnol 56:220-224

Jaworska M, Konieczna E (2004) Kinetyka enzymatycznej deacetylacji chitozanu. Inz Chem Proc 25:1029-1034

Jaworska MM, Bryjak J, Liesiene J (2009) A search for an optimal carrier for immobilization of chitin deacetylase. Cellulose 16:261-270

Martinou A, Bouriotis V, Stokke BT, Varum KM (1998) Mode of action of chitin deacetylase from Mucor rouxii on partially N-acetylated chitosan. Carbohydrate Res 311:71-78

Tokuyasu K, Ohnishi-Kameyama M, Hayashi K (1996) Purification and characterization of extracellular chitin deacetylase from Colletotrichum lindemuthianum. Biosci Biotech Biochem 30:239-242

Tsigos I, Martinou A, Kafetzopoulos D, Bouriotis V (2000) Chitin deacetylases: new, versatile tools in biotechnology. TIBTECH 18:305-312 